\title{
C-fiber-Selective Peripheral Nerve Blockade
}

\author{
Suzuko Suzuki ${ }^{1, *}$, Peter Gerner $^{2}$, Anna C Colvin ${ }^{3}$ and Alexander M. Binshtok ${ }^{4}$
}

\begin{abstract}
${ }^{I}$ Department of Anesthesiology and Perioperative Medicine, Pain Research Center, Brigham and Women's Hospital, MRB-611 75 Francis Street, Boston, MA 02115; ${ }^{2}$ Department of Anesthesiology, Perioperative, and Pain Medicine, Brigham and Women's Hospital and Harvard Medical School, Boston, MA; ${ }^{3}$ Department of Anesthesiology, Perioperative, and Pain Medicine, Brigham and Women's Hospital and Harvard, Medical School, Boston, MA; ${ }^{4}$ Department of Anesthesia, and Critical Care, Massachusetts General Hospital and Harvard, Medical School, Charlestown, MA
\end{abstract}

\begin{abstract}
Despite the clinical demand, current uses of local anesthetics do not allow selective blockade of nociceptive fibers. Regional anesthesia produces an analgesic effect accompanied with undesired side effects due to block of motor, non-nociceptive sensory and autonomic fibers. These side effects limit the clinical use of local anesthetics and affect the recovery and rehabilitation period after surgical procedures. Therefore one main goal of research in the field of regional anesthesia is selectively targeting nociceptive fibers. Recent studies describing the role of nociceptive specific sodium channels in generation and propagation of nociceptive signals make these channels ideal targets for pain selective blockade. In addition, novel methods of targeted delivery of charged local anesthetics selectively into nociceptors provide another potentially successful approach for c-fiber specific nerve block. This review summarizes currently on-going studies on several promising targets and methods to achieve pain selective anesthesia.
\end{abstract}

\section{INTRODUCTION}

Local anesthetics (LAs) are frequently used in clinical practice when anesthesia of limited body area is desired. LAs block voltage-gated sodium channels, thereby preventing generation of action potentials and their propagation along the nerve [1]. However, LAs block sodium channels not only in sensory fibers but also in motor and sympathetic fibers. To date, no agent or method translatable into current clinical practice has been shown to elicit usable pain-selective nerve blocks. In general, clinicians agree that there is a slight but detectable difference among local anesthetics in motor vs. sensory blockade; e.g., bupivacaine in general has somewhat more sensory/nociceptive block than motor block, while etidocaine confers more motor than sensory block. The following pages review treatments that are far more selective or exclusively pain-fiber selective than currently used clinical and experimental local anesthetics. Nociceptive-selective nerve block has been attempted with concentrations of LAs that are high enough for only certain nerve fibers (smallerdiameter, thinly myelinated A-delta or unmyelinated Cfibers), but not for others (larger-diameter, myelinated nerves such as A-beta). Nevertheless, studies have demonstrated that nerve block does not always follow this size principle, and motor fibers are blocked before nociceptive fibers [2]. Therefore, complete pain relief is generally accomplished only with simultaneous low-threshold sensory sympathetic and motor blockade, leading to numerous adverse effects. Improving the sensory-selectivity of LAs will clearly extend their clinical utility. (Of note, especially in the clinical

*Address correspondence to this author at the Department of Anesthesiology and Perioperative Medicine, Pain Research Center, Brigham and Women's Hospital, MRB-611 75 Francis Street, Boston, MA 02115;

E-mail: ssuzuki@zeus.bwh.harvard.edu anesthesia literature, the terms "sensory-selective" and "differential block" are commonly used and are roughly interchangeable with "pain-selective" and "nociceptorselective.") We review novel methods to achieve nociceptorselective peripheral nerve blockade.

Considering the properties of pain-specific peripheral nerve fibers is fundamental in exploring differential nerve blockade. Noxious stimuli are received and interpreted by selective-type peripheral sensory neurons, i.e. nociceptors. Nociceptors are unique among other peripheral neurons for their expression of high-threshold transducer receptors that transform noxious chemical, thermal, and/or mechanical stimuli into electrical signals [3]. Those receptors include channels from the transient receptor potential family; TRPV1, V2, M8, A1, and the purinoreceptor P2X [4-6]. TRPV1, V2, and M8 are involved in perception of heat $[4$, $5,7,8]$, and A1 is involved in sensing various chemical irritants [9]. Purinoreceptor P2X is activated by the presence of ATP [10]. The activation of these receptors results in ion influx and depolarization of the membrane of the nerve terminal [11]. If the depolarization is strong enough to activate sodium channels, it will result in action potentials that propagate along A delta and $\mathrm{C}$ fibers. These nociceptors express a unique repertoire of sodium channels including both TTX-sensitive and -resistant subtypes. A-delta fibers are associated with transmission of superficial, sharp pain. The $\mathrm{C}$ fibers are associated with transmission of dull, throbbing pain [12]. It is now agreed that within the peripheral nervous system C-fibers express TRPV1and $\mathrm{Na}_{(\mathrm{v})} 1.7$ almost exclusively [13-17]. Therefore this review focuses mainly on TRPV1 and $\mathrm{Na}_{(\mathrm{v})} 1.7$.

\section{TRPV1 CHANNELS}

The vanilloid receptor subtype 1 (VR1) (TRPV1) is a member of the superfamily of transient receptor potential ion 
channels [4]. TRPV1 is expressed peripherally in primary afferent nociceptors [13] and is stimulated and sensitized by noxious heat, protons, and various inflammatory mediators that comprise the 'inflammatory soup' including bradykinin, adenosine triphosphate and arachidonic acid derivatives such as prodtagrandings and leukotriene B4 [3]. TRPV1 is a nonselective cation channel that permits calcium and sodium ions to pass through the membrane of the primary sensory/ nociceptive neurons, causing membrane depolarization and leading to nociceptive responses. However, initial excitation of the nociceptive neuron by capsaicin is followed by a long refractory state, including desensitization of the receptor or channel,changes in axon terminals, mitochondrial swelling, release of calcitonin gene-related peptide, displacement of adenosine triphosphate by the calcium sensor calmodulin, depletion of substance $\mathrm{P}$, and, at higher concentrations, the possibility of axonal atrophy and terminal degeneration [1820]. This desensitization and the longer-lasting atrophic/ degenerative changes led to clinical use of capsaicin in topical ointments to relieve neuropathic pain such as postherpetic neuralgia and minor aches and pains associated with arthritis, strains, and sprains [19]. A single high-dose local injection of capsaicin is also currently being investigated for controlling post-surgical and osteoarthritis pain[19].

The ultrapotent TRPV1 agonist RTX has also been wellstudied and is currently clinically used to treat certain urological conditions such as bladder hyperactivity [21-25]. As a TRPV1 activator, RTX is known to be 20 -fold more potent than capsaicin [4] and, similar to capsaicin, produces prolonged membrane depolarization of TRPV1-laden nerve fibers. The peripheral injection of RTX has been shown to prevent development of thermal and mechanical allodynia in inflammatory rat pain models [26-29].

Recently Binshtok et al. postulated that activation of the TRPV1 channel allows otherwise impermeant molecules such as QX-314, a bulky positively charged lidocaine derivative, to enter the nerve cells (Fig. 1). Indeed, in a rat sciatic nerve block model, the injection of QX-314 followed by capsaicin demonstrated an expected nociceptor-selective, long-lasting blockade while leaving motor impulse conduction intact. [30] Moreover, such an activation of TRPV1 channels will lead to a predominantly nociceptor-selective blockade with experimental (amitriptyline or $\mathrm{N}$-methyl amitriptyline) and clinically used (lidocaine and bupivacaine) LA agents [31].

In addition, the narrow dosage range within which LAs such as lidocaine and bupivacaine can be safely administered without significant toxicity is one of the most severely limiting aspects of these drugs in clinical practice. For instance, the dose of lidocaine that produces toxic effects is only several folds greater than the dose necessary to produce a therapeutic effect. The therapeutic ranges of capsaicin and RTX are known to be two and three orders of magnitude greater, respectively [32]. The combination of LAs with capsaicin allows lower concentration of LAs to achieve the desired effect and hence increases their safety margin. Nevertheless, whether the facilitation of LAs by TRPV1 agonists is accompanied by proportionally increased cellular toxic effects has yet to be determined.

One clinically limiting aspect of these agents is the initial burning sensation when they are applied topically. The combined use of capsaicin with LA has the additional benefit of 'anesthetizing' the nerve first, preventing the burning sensation. Furthermore, at least in rats, the subcutaneous or sciatic perineural injection of high concentrations of capsaicin $(0.1 \%)$ or RTX $(0.001 \%)$, administered with clinically used LAs like lidocaine or bupivacaine to awake animals, does not elicit any immediate behavioral changes suggestive of pain expected of the initial activation of TRPV1 by these agents (Gerner, P. unpublished results).

Similarly, other high-conductance nociceptive-selective nonspecific cation transducer channels could be used to produce nociceptive-selective local anesthesia.

\section{SODIUM CHANNELS}

Each sodium channel consists of a large functional alphasubunit and one or two much smaller auxiliary beta-subunits. Subtypes of sodium channels arise from variation in the

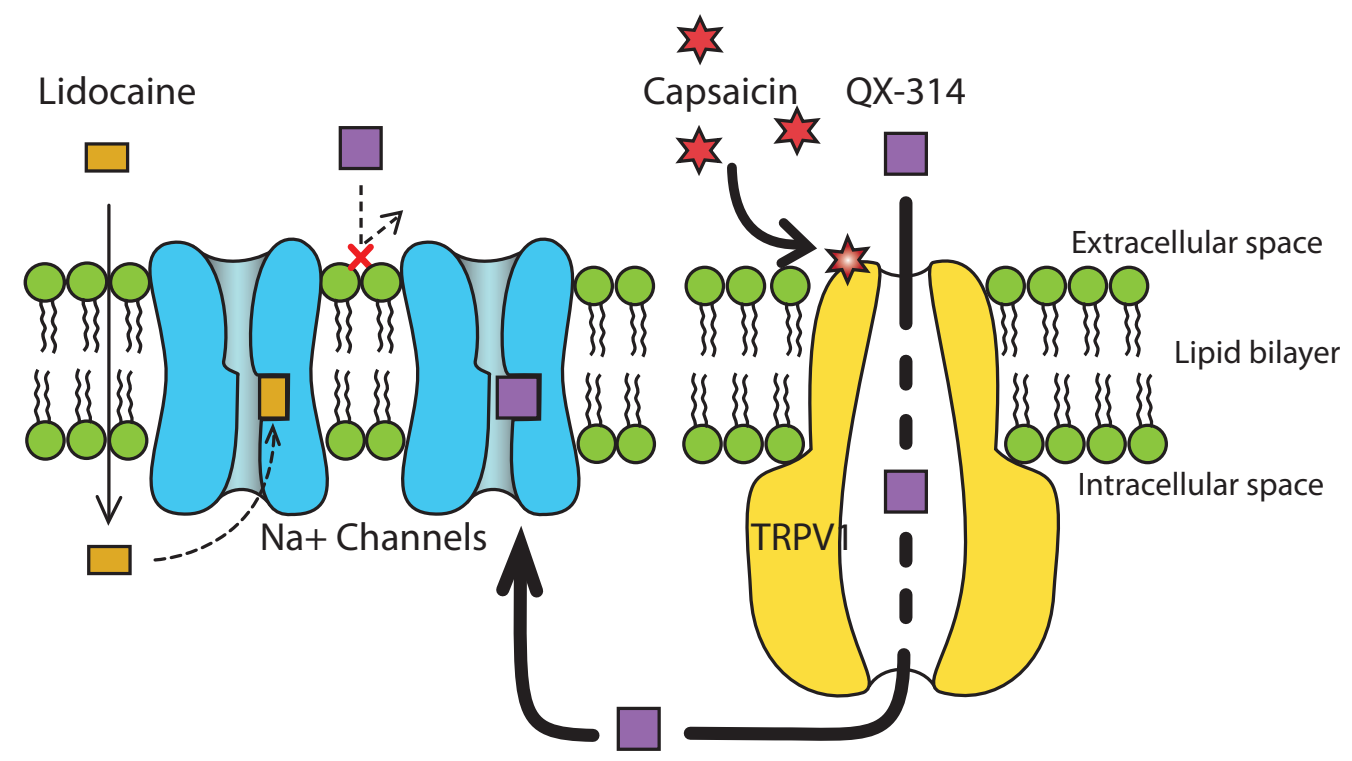

Fig. (1). Hypothesized mechanism of QX-314's entry into the nerve. The activation of the TRPV1 channels opens the pore, allowing molecules such as QX-314 enter the cell to block the sodium channel. 
homologous alpha-subunit genes. The nine subtypes now known in mammals $\left(\mathrm{Na}_{(\mathrm{v})} 1.1\right.$ through 1.9) are differentially expressed in various tissues, which suggests their functional correlation. For example, multiple subtypes of sodium channels in the dorsal root ganglion (DRG) are believed to be involved in multiple events along the pain pathway such as transmission, signal amplification, and action potential electrogenesis. Nociceptors express several types of sodium channels including both TTX-sensitive $(\mathrm{Na}(\mathrm{v})$ 1.1, 1.6, 1.7 and 1.3) and TTX-resistant $\left(\mathrm{Na}_{(\mathrm{v})} 1.8\right.$ and 1.9) subtypes. Some of the sodium channels such as $\mathrm{Na}_{(\mathrm{v})} 1.8, \mathrm{Na}_{(\mathrm{v})} 1.9$, and $\mathrm{Na}_{(\mathrm{v})} 1.7$ are expressed exclusively on peripheral [33-35] but not vagal [36] nociceptors.

Currently the "hottest" target for nociceptive-specific blockade is the $\mathrm{Na}_{(\mathrm{v})} 1.7$ channel, since this subtype determines the ability of a nerve to transmit pain sensation [37].

The importance of $\mathrm{Na}_{(\mathrm{v})} 1.7$ has become increasingly evident through genetic correlation of this channel with congenital abnormality of pain perception [38]. Loss-offunction mutations of $\mathrm{Na}_{(\mathrm{v})} 1.7$ are reported in patients with channelopathy-associated insensitivity, in which patients have isolated lack of sensory function for pain and smell [37]. On the other hand, several gain-of-function mutations of genes related to the regulation or function of $\mathrm{Na}_{(\mathrm{v})} 1.7$, resulting in over-activity of this channel, are found in patients with two painful congenital disorders, erythermalgia (also termed erythermelalgia) and paroxysmal extreme pain disorder, congenital conditions whereby patients are afflicted by episodic severe pain attacks accompanied by cutaneous flushing [39-41]. $\mathrm{Na}_{(\mathrm{v})} 1.7$ also appears to be involved in the development of inflammatory pain, as demonstrated in an animal study that showed inflammation-induced upregulation of $\mathrm{Na}_{(\mathrm{v})} 1.7$ in the DRG [42]. Furthermore, a recent preclinical study has reported that ProTX-II, a $\mathrm{Na}_{(\mathrm{v})} 1.7-$ selective antagonist from spider venom, prevented the propagation of action potentials in small-diameter nociceptive fibers, while larger fibers remained intact [43]. The further identification of such a selective $\mathrm{Na}_{(\mathrm{v})} 1.7$ blocker is an area of great interest.

$\mathrm{Na}_{(\mathrm{v})} 1.8$ is expressed predominantly in small nociceptive neurons [34] and has been demonstrated to be the main source of sodium influx during action potential electrogenesis [44, 45]. Knock-out (KO) studies demonstrated that this channel also underlies the ability of nociceptive neurons to fire repetitively [46]. Accumulating evidence has shown the intimate relationship of $\mathrm{Na}_{\text {(v) }} 1.8$ to generation of inflammatory and neuropathic pain [46-51]. The injection of complete Freund's adjuvant or carageenan increased expression of $\mathrm{Na}_{\text {(v) }} 1.8$ in the rat DRG. In mice, knocking down the $\mathrm{Na}_{(\mathrm{v})} 1.8$ gene by antisense oligonucleotides attenuated the development of inflammatory hyperalgesia [52,53]. Currently A-803467, a Na(v) 1.8 -selective blocker, has been shown to attenuate mechanical allodynia in a dosedependent fashion in animal pain models including sciatic nerve injury, spinal nerve ligation, and chemically induced thermal allodynia and secondary allodynia [51, 54]. Ambroxol, a relatively selective blocker of $\mathrm{Na}_{(\mathrm{v})} 1.8$. has also been shown to produce effective analgesia in inflammatory and neuropathic pain models in animals[55]. Another subtype,
$\mathrm{Na}_{(\mathrm{v})} 1.9$, is also found only in small DRG neurons [51, 5658]. $\mathrm{Na}_{(\mathrm{v})} 1.9$ is thought to be responsible for a slow persistent sodium current with low threshold and activated over a wide range of voltage. This current is postulated to influence the subthreshold excitable properties of the membrane, which may explain the mechanism of sensitization by causing the membrane resting potential to fluctuate $[46,49$, 57, 59]. In addition, $\mathrm{Na}_{(\mathrm{v})} 1.9 \mathrm{KO}$ mice failed to display inflammation-induced excitability or up-regulation of $\mathrm{Na}+$ channels[60]. Subsequent introduction of cloned $\mathrm{Na}_{(\mathrm{v})} 1.9$ reinstituted this effect[60].

The differential effect on nociceptive-specific sodium channels may also underlie the analgesic effects of some anticonvulsants and antidepressants. For example, Lacosamide is an anticonvulsant that also has $\mathrm{Na}_{(\mathrm{v})} 1.8$-blocking properties and has been shown to be effective in treating neuropathic pain in preclinical studies[61].

The restricted expression of sodium channels $\mathrm{Na}_{\mathrm{v}} 1.7$, $\mathrm{Na}_{\mathrm{v}} 1.8$, and $\mathrm{Na}_{\mathrm{v}} 1.9$ on peripheral nociceptors and the direct link of Nav1.7 to pain states in humans make them ideal targets for development of more effective drugs with fewer undesirable side effects. However, since specific blockers of sodium channels demonstrate low bioavailability, none of the existing compounds have proven suitable for clinical use. Recently demonstrated expression of TTX-resistant sodium channels on A-fibers of nodose vagal sensory neurons reduce the selectivity of these specific blockers to nociceptors [36]. Moreover, chronic pain disorders are multifactorial, and the efficacy of drugs is also greatly influenced by the up- and down-regulation of various sodium channel subtypes in the different stages of inflammatory and neuropathic pain [50, 62-66].

Therefore the approaches targeting sodium channel blockers specifically to nociceptive neurons are preferable.

\section{FUTURE STUDIES}

Many compounds targeting specific sodium channel subtypes have been identified and are currently awaiting detailed testing in vivo in various models. Among them, the above-mentioned A-803467 appears promising in treating neuropathic and inflammatory pain. However, no clinical trials are currently underway using this agent (clinicaltrials.gov). Lacosamide is now under phase 3 clinical trials for mainly neuropathic pain such as painful diabetic neuropathy, migraine, and post-herpetic neuralgia. Ralfinamide is also in phase 2 clinical trials for various neuropathic pain conditions.

Besides capsaicin and RTX, further interest in nociceptive-selective blockade may be explored among the members of TRP ion channel family agonists or antagonists. Given the suggested critical role of TRP channels in the pain pathways in both the central and peripheral nervous systems, the surge of interest in the TRP family as a target for the next generation of analgesic agents has led to the discovery of numerous TRP agonists and antagonists. Some of the clinically used local and inhalation anesthetic agents are now known to be TRPV1 and TRPA1 agonists, including lidocaine, tramadol, and isoflurane [67-69]. These agents may generate synergistic differential analgesic effects with other local or general anesthetics through mechanisms similar to 
RTX and capsaicin and are potential candidates for future studies to achieve differential nerve block. However, one drawback is that manipulation of TRPV1 activity also affects its thermoregulatory function. It has been demonstrated in both human and animal studies that TRPV1 blockade can lead to hyperthermia in susceptible individuals [70, 71]. These results obviously pose significant challenges to the clinical use of TRPV1 antagonists. Nonetheless, these results are informative for future study of the role of TRPV1 channel activation in thermoregulatory processes. Further research will hopefully identify other, more selective TRPV1 antagonists that they interfere only with the nociceptive transmission while sparing other TRPV1-mediated activities.
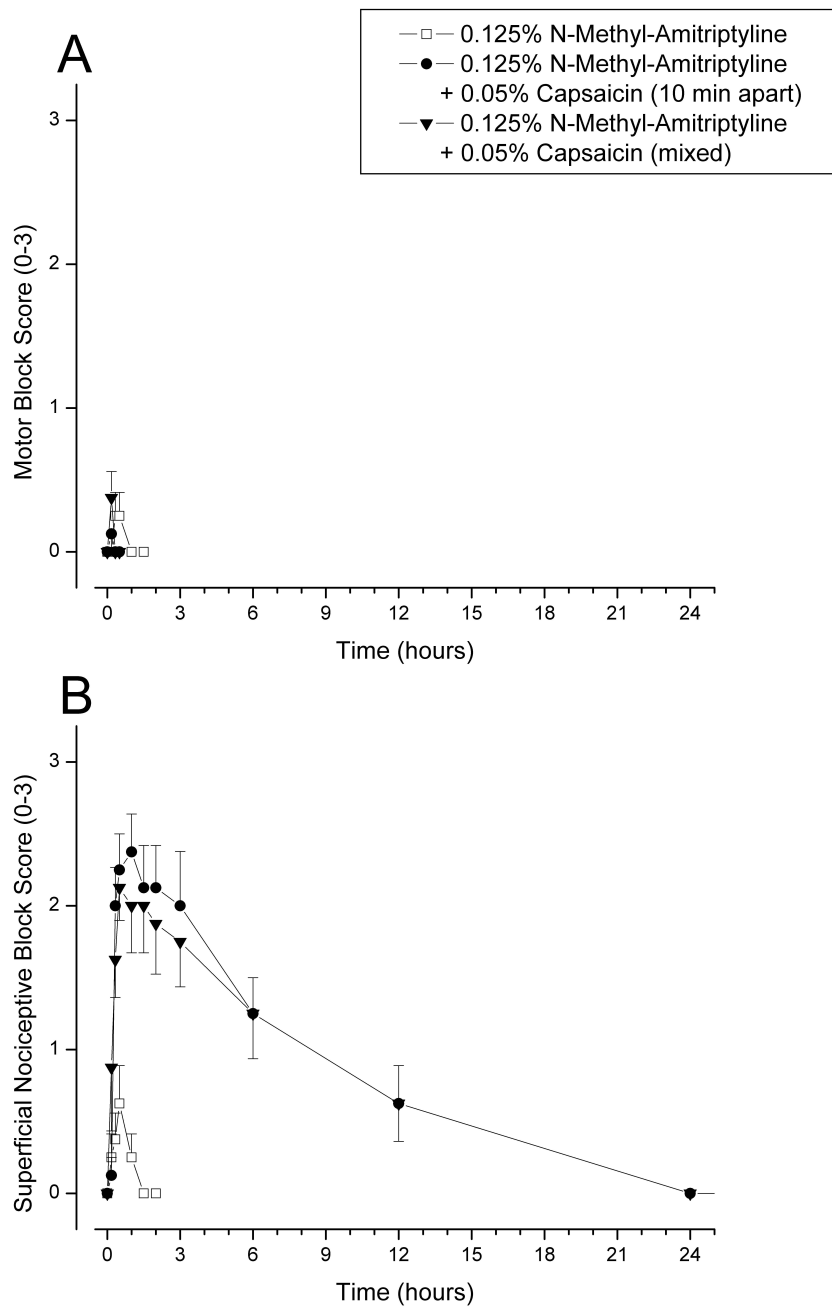

Fig. (2). Sciatic nerve block with $0.2 \mathrm{ml}$ of $\mathrm{N}$-methyl amitriptyline at $0.125 \%$, alone or in combination with $0.05 \%$ capsaicin (simultaneously applied/mixed or $10 \mathrm{~min}$ later), $\mathrm{n}=8$ rats per group. Data are presented as mean \pm SE. A. Motor Block Score (0-3): Motor function was assayed by a digital platform balance. $0=$ no block (or baseline); 1 = minimal block; 2 = moderate block; 3 = complete block (force of $20 \mathrm{~g}$ or less). B. Superficial Nociceptive Block Score (0-3): Nociception was evaluated by the nocifensive withdrawal reflex and vocalization to pinch of a skin fold. $3=$ complete block, no nocifensive reaction or vocalization; 2 = moderate block, vocalization accompanied by slow withdrawal and flexion of the leg; 1 = minimal block, brisk flexion of the leg, with some sideways movement of the body or other escape response and loud vocalization; $0=$ baseline with no block and all nocifensive responses listed above.
Besides identifying drugs for pain-specific sodium channel subtypes and/or TRPV1 agonist/antagonists, and combining TRPV1 channel agonists with permanently charged LAs (Fig. 2), another future approach might be to combine TRPV1 channel agonists with specific positively charged sodium channel subtype antagonists to further maximize pain selectivity. The combination of a TRPV1 agonist and LA is currently awaiting regulatory approval for clinical trials.

In summary, several approaches are currently being pursued in the development of agents for C-fiber-selective peripheral nerve blockade. A considerable amount of effort has been put into identification of compounds specific for sodium channel subtypes and TRP agonists as well as antagonists. An exciting new approach is combining TRPV1 agonists with permanently charged large LA molecules, [31] selectively allowing these otherwise impermeable compounds only into C-fibers.

\section{REFERENCES}

[1] Strichartz GR, Berde CB. Local Anesthetics. In: Miller R.D, Ed. Miller's Anesthesia. $6^{\text {th }}$ ed. New York: Churchill Livingstone; 2004; pp. 573-603.

[2] Gokin AP, Philip B, Strichartz GR. Preferential block of small myelinated sensory and motor fibers by lidocaine: in vivo electrophysiology in the rat sciatic nerve. Anesthesiology 2001; 95(6): 1441-54.

[3] Woolf CJ, Ma Q. Nociceptors--noxious stimulus detectors. Neuron 2007; 55(3): 353-64.

[4] Caterina MJ, Schumacher MA, Tominaga M, Rosen TA, Levine JD, Julius D. The capsaicin receptor: a heat-activated ion channel in the pain pathway. Nature 1997; 389(6653): 816-24.

[5] Lawson JJ, McIlwrath SL, Woodbury CJ, Davis BM, Koerber HR. TRPV1 unlike TRPV2 is restricted to a subset of mechanically insensitive cutaneous nociceptors responding to heat. J Pain 2008; 9(4): 298-308.

[6] Jordt SE, Bautista DM, Chuang HH, et al. Mustard oils and cannabinoids excite sensory nerve fibres through the TRP channel ANKTM1. Nature 2004; 427(6971): 260-5.

[7] Peier AM, Moqrich A, Hergarden AC, et al. A TRP channel that senses cold stimuli and menthol. Cell 2002; 108(5): 705-15.

[8] Souslova V, Cesare P, Ding Y, et al. Warm-coding deficits and aberrant inflammatory pain in mice lacking $\mathrm{P} 2 \mathrm{X} 3$ receptors. Nature 2000; 407(6807): 1015-7.

[9] Macpherson LJ, Xiao B, Kwan KY, et al. An ion channel essential for sensing chemical damage. J Neurosci 2007; 27(42): 11412-5.

[10] Burnstock G, Wood JN. Purinergic receptors: their role in nociception and primary afferent neurotransmission. Curr Opin Neurobiol 1996; 6(4): 526-32.

[11] Julius D, Basbaum AI. Molecular mechanisms of nociception. Nature 2001; 413(6852): 203-10.

[12] Butterworth JF, Strichartz GR. Molecular mechanisms of local anesthesia: a review. Anesthesiology 1990; 72(4): 711-34.

[13] Tominaga M, Caterina MJ, Malmberg AB, et al. The cloned capsaicin receptor integrates multiple pain-producing stimuli. Neuron 1998; 21(3): 531-43.

[14] Toledo-Aral JJ, Moss BL, He ZJ, et al. Identification of PN1, a predominant voltage-dependent sodium channel expressed principally in peripheral neurons. Proc Natl Acad Sci USA 1997; 94(4): 1527-32.

[15] Felts PA, Yokoyama S, Dib-Hajj S, Black JA, Waxman SG. Sodium channel alpha-subunit mRNAs I, II, III, NaG, Na6 and hNE (PN1): different expression patterns in developing rat nervous system. Brain Res Mol Brain Res 1997; 45(1): 71-82.

[16] Djouhri L, Newton R, Levinson SR, Berry CM, Carruthers B, Lawson SN. Sensory and electrophysiological properties of guinea- 
pig sensory neurones expressing Nav 1.7 (PN1) Na+ channel alpha subunit protein. J Physiol 2003; 546(Pt 2): 565-76.

[17] Sangameswaran L, Fish LM, Koch BD, et al. A novel tetrodotoxinsensitive, voltage-gated sodium channel expressed in rat and human dorsal root ganglia. J Biol Chem 1997; 272(23): 14805-9.

[18] Gibson SJ, McGregor G, Bloom SR, Polak JM, Wall PD. Local application of capsaicin to one sciatic nerve of the adult rat induces a marked depletion in the peptide content of the lumbar dorsal horn. Neuroscience 1982; 7(12): 3153-62.

[19] Knotkova H, Pappagallo M, Szallasi A. Capsaicin (TRPV1 Agonist) Therapy for Pain Relief: Farewell or Revival? Clin J Pain 2008; 24(2): 142-54.

[20] Cortright DN, Krause JE, Broom DC. TRP channels and pain. Biochim Biophys Acta 2007; 1772(8): 978-88.

[21] Cruz F, Dinis P. Resiniferatoxin and botulinum toxin type A for treatment of lower urinary tract symptoms. Neurourol Urodyn 2007; 26(6 Suppl): 920-7.

[22] Cruz CD, Charrua A, Vieira E, Valente J, Avelino A, Cruz F. Intrathecal delivery of resiniferatoxin (RTX) reduces detrusor overactivity and spinal expression of TRPV1 in spinal cord injured animals. Exp Neurol 2008; 214(2): 301-8.

[23] MacDonald R, Monga M, Fink HA, Wilt TJ. Neurotoxin treatments for urinary incontinence in subjects with spinal cord injury or multiple sclerosis: a systematic review of effectiveness and adverse effects. J Spinal Cord Med 2008; 31(2): 157-65.

[24] Saitoh C, Chancellor MB, de Groat WC, Yoshimura N. Effects of intravesical instillation of resiniferatoxin on bladder function and nociceptive behavior in freely moving, conscious rats. J Urol 2008; 179(1): 359-64.

[25] Mourtzoukou EG, Iavazzo C, Falagas ME. Resiniferatoxin in the treatment of interstitial cystitis: a systematic review. Int Urogynecol J Pelvic Floor Dysfunct 2008; 19(11): 1571-6.

[26] Kissin I, Bright CA, Bradley EL, Jr. Selective and long-lasting neural blockade with resiniferatoxin prevents inflammatory pain hypersensitivity. Anesth Analg 2002; 94(5): 1253-8.

[27] Kissin I, Davison N, Bradley EL, Jr. Perineural resiniferatoxin prevents hyperalgesia in a rat model of postoperative pain. Anesth Analg 2005; 100(3): 774-80.

[28] Kissin I, Freitas CF, Bradley EL, Jr. Memory of pain: the effect of perineural resiniferatoxin. Anesth Analg 2006; 103(3): 721-8.

[29] Kissin I, Freitas CF, Bradley EL, Jr. Perineural resiniferatoxin prevents the development of hyperalgesia produced by loose ligation of the sciatic nerve in rats. Anesth Analg 2007; 104(5): 1210-6.

[30] Binshtok AM, Bean BP, Woolf CJ. Inhibition of nociceptors by TRPV1-mediated entry of impermeant sodium channel blockers. Nature 2007; 449(7162): 607-10.

[31] Gerner P, Binshtok AM, Wang CF, et al. Capsaicin combined with local anesthetics preferentially prolongs sensory/nociceptive block in rat sciatic nerve. Anesthesiology 2008; 109(5): 872-8.

[32] Kissin I. Vanilloid-induced conduction analgesia: selective, dosedependent, long-lasting, with a low level of potential neurotoxicity. Anesth Analg 2008; 107(1): 271-81.

[33] Djouhri L, Fang X, Okuse K, Wood JN, Berry CM, Lawson SN. The TTX-resistant sodium channel Nav1.8 (SNS/PN3): expression and correlation with membrane properties in rat nociceptive primary afferent neurons. J Physiol 2003; 550(Pt 3): 739-52.

[34] Akopian AN, Sivilotti L, Wood JN. A tetrodotoxin-resistant voltage-gated sodium channel expressed by sensory neurons. Nature 1996; 379(6562): 257-62.

[35] Black JA, Dib-Hajj S, McNabola K, et al. Spinal sensory neurons express multiple sodium channel alpha-subunit mRNAs. Brain Res Mol Brain Res 1996; 43(1-2): 117-31.

[36] Kwong K, Carr MJ, Gibbard A, et al. Voltage-gated sodium channels in nociceptive versus non-nociceptive nodose vagal sensory neurons innervating guinea pig lungs. J Physiol 2008; 586(5): 1321-36.

[37] Cox JJ, Reimann F, Nicholas AK, et al. An SCN9A channelopathy causes congenital inability to experience pain. Nature 2006; (7121): 894-8.
[38] Yang Y, Wang Y, Li S, et al. Mutations in SCN9A, encoding a sodium channel alpha subunit, in patients with primary erythermalgia. J Med Genet 2004; 41(3): 171-4.

[39] Dib-Hajj SD, Estacion M, Jarecki BW, et al. Paroxysmal extreme pain disorder M1627K mutation in human Nav1.7 renders DRG neurons hyperexcitable. Mol Pain 2008; 4:37.

[40] Jarecki BW, Sheets PL, Jackson JO, Cummins TR. Paroxysmal extreme pain disorder mutations within the D3/S4-S5 linker of Nav1.7 cause moderate destabilization of fast inactivation. J Physiol 2008; 586(Pt 17): 4137-53.

[41] Estacion M, Dib-Hajj SD, Benke PJ, et al. NaV1.7 gain-of-function mutations as a continuum: A1632E displays physiological changes associated with erythromelalgia and paroxysmal extreme pain disorder mutations and produces symptoms of both disorders. J Neurosci 2008; 28(43): 11079-88.

[42] Black JA, Liu S, Tanaka M, Cummins TR, Waxman SG. Changes in the expression of tetrodotoxin-sensitive sodium channels within dorsal root ganglia neurons in inflammatory pain. Pain 2004; 108(3): 237-47.

[43] Schmalhofer WA, Calhoun J, Burrows R, et al. ProTx-II, a selective inhibitor of NaV1.7 sodium channels, blocks action potential propagation in nociceptors. Mol Pharmacol 2008; 74(5): 1476-84.

[44] Renganathan M, Cummins TR, Waxman SG. Contribution of $\mathrm{Na}(\mathrm{v}) 1.8$ sodium channels to action potential electrogenesis in DRG neurons. J Neurophysiol 2001; 86(2): 629-40.

[45] Blair NT, Bean BP. Roles of tetrodotoxin (TTX)-sensitive $\mathrm{Na}+$ current, TTX-resistant $\mathrm{Na}+$ current, and $\mathrm{Ca} 2+$ current in the action potentials of nociceptive sensory neurons. J Neurosci 2002; 22(23): 10277-90.

[46] Akopian AN, Souslova V, England S, et al. The tetrodotoxinresistant sodium channel SNS has a specialized function in pain pathways. Nat Neurosci 1999; 2(6): 541-8.

[47] Coward K, Plumpton C, Facer $\mathrm{P}$, et al. Immunolocalization of SNS/PN3 and NaN/SNS2 sodium channels in human pain states. Pain 2000; 85(1-2): 41-50.

[48] Laird JM, Souslova V, Wood JN, Cervero F. Deficits in visceral pain and referred hyperalgesia in Nav1.8 (SNS/PN3)-null mice. J Neurosci 2002; 22(19): 8352-6.

[49] Amaya F, Shimosato G, Kawasaki Y, et al. Induction of CB(1) cannabinoid receptor by inflammation in primary afferent neurons facilitates antihyperalgesic effect of peripheral $\mathrm{CB}(1)$ agonist. Pain 2006; 124(1-2): 175-83.

[50] Amir R, Argoff CE, Bennett GJ, et al. The role of sodium channels in chronic inflammatory and neuropathic pain. J Pain 2006; 7(5 Suppl 3): S1-29.

[51] Jarvis MF, Honore P, Shieh CC, et al. A-803467, a potent and selective Nav1.8 sodium channel blocker, attenuates neuropathic and inflammatory pain in the rat. Proc Natl Acad Sci USA 2007; 104(20): 8520-5.

[52] Yoshimura N, Seki S, Novakovic SD, et al. The involvement of the tetrodotoxin-resistant sodium channel $\mathrm{Na}(\mathrm{v}) 1.8$ (PN3/SNS) in a rat model of visceral pain. J Neurosci 2001; 21(21): 8690-6.

[53] Porreca F, Lai J, Bian D, et al. A comparison of the potential role of the tetrodotoxin-insensitive sodium channels, PN3/SNS and NaN/SNS2, in rat models of chronic pain. Proc Natl Acad Sci USA 1999; 96(14): 7640-4.

[54] McGaraughty S, Chu KL, Scanio MJ, Kort ME, Faltynek CR, Jarvis MF. A selective Nav1.8 sodium channel blocker, A-803467 [5-(4-chlorophenyl-N-(3,5-dimethoxyphenyl)furan-2-

carboxamide], attenuates spinal neuronal activity in neuropathic rats. J Pharmacol Exp Ther 2008; 324(3): 1204-11.

[55] Gaida W, Klinder K, Arndt K, Weiser T. Ambroxol, a Nav1.8preferring $\mathrm{Na}(+)$ channel blocker, effectively suppresses pain symptoms in animal models of chronic, neuropathic and inflammatory pain. Neuropharmacology 2005; 49(8): 1220-7.

[56] Dib-Hajj SD, Black JA, Cummins TR, Kenney AM, Kocsis JD, Waxman SG. Rescue of alpha-SNS sodium channel expression in 
small dorsal root ganglion neurons after axotomy by nerve growth factor in vivo. J Neurophysiol 1998; 79(5): 2668-76.

[57] Wood JN, Boorman JP, Okuse K, Baker MD. Voltage-gated sodium channels and pain pathways. J Neurobiol 2004; 61(1): 5571.

[58] Fang X, Djouhri L, McMullan S, et al. Intense isolectin-B4 binding in rat dorsal root ganglion neurons distinguishes $\mathrm{C}$-fiber nociceptors with broad action potentials and high Nav1.9 expression. J Neurosci 2006; 26(27): 7281-92.

[59] Waxman SG, Estacion M. Nav1.9, G-proteins, and nociceptors. J Physiol 2008; 586(4): 917-8.

[60] Ostman JA, Nassar MA, Wood JN, Baker MD. GTP up-regulated persistent $\mathrm{Na}+$ current and enhanced nociceptor excitability require NaV1.9. J Physiol 2008; 586(4): 1077-87.

[61] Sheets PL, Heers C, Stoehr T, Cummins TR. Differential block of sensory neuronal voltage-gated sodium channels by lacosamide [(2R)-2-(acetylamino)-N-benzyl-3-methoxypropanamide],

lidocaine, and carbamazepine. J Pharmacol Exp Ther 2008; 326(1): 89-99.

[62] Lai J, Porreca F, Hunter JC, Gold MS. Voltage-gated sodium channels and hyperalgesia. Annu Rev Pharmacol Toxicol 2004; 44: 371-97.

[63] Carter AJ, Grauert M, Pschorn U, et al. Potent blockade of sodium channels and protection of brain tissue from ischemia by BIII 890 CL. Proc Natl Acad Sci USA 2000; 97(9): 4944-9.
[64] Waxman SG, Cummins TR, Dib-Hajj S, Fjell J, Black JA. Sodium channels, excitability of primary sensory neurons, and the molecular basis of pain. Muscle Nerve 1999; 22(9): 1177-87.

[65] Yu FH, Catterall WA. Overview of the voltage-gated sodium channel family. Genome Biol 2003; 4(3): 207.

[66] Goldin AL. Resurgence of sodium channel research. Annu Rev Physiol 2001; 63: 871-94.

[67] Marincsak R, Toth BI, Czifra G, Szabo T, Kovacs L, Biro T. The analgesic drug, tramadol, acts as an agonist of the transient receptor potential vanilloid-1. Anesth Analg 2008; 106(6): 1890-6.

[68] Leffler A, Fischer MJ, Rehner D, et al. The vanilloid receptor TRPV1 is activated and sensitized by local anesthetics in rodent sensory neurons. J Clin Invest 2008; 118(2): 763-76.

[69] Matta JA, Cornett PM, Miyares RL, Abe K, Sahibzada N, Ahern GP. General anesthetics activate a nociceptive ion channel to enhance pain and inflammation. Proc Natl Acad Sci USA 2008; 105(25): 8784-9.

[70] Gavva NR, Treanor JJ, Garami A, et al. Pharmacological blockade of the vanilloid receptor TRPV1 elicits marked hyperthermia in humans. Pain 2008; 136(1-2): 202-10.

[71] Steiner AA, Turek VF, Almeida MC, et al. Nonthermal activation of transient receptor potential vanilloid-1 channels in abdominal viscera tonically inhibits autonomic cold-defense effectors. J Neurosci 2007; 27(28): 7459-68. 